\title{
Photocatalytic Degradation of Monolinuron and Linuron in an Aqueous Suspension of Titanium Dioxide Under Simulated Solar Irradiation
}

\section{Dégradation photocatalytique du monolinuron et du linuron dans une suspension aqueuse de dioxide de titanium au contact de lumière solaire simulée}

\author{
Razika Zouaghi, Abdennour Zertal, Bernard David et Sylvie Guittonneau
}

Volume 20, numéro 2, 2007

URI : https://id.erudit.org/iderudit/015810ar

DOI : https://doi.org/10.7202/015810ar

Aller au sommaire du numéro

\section{Éditeur(s)}

Université du Québec - INRS-Eau, Terre et Environnement (INRS-ETE)

\section{ISSN}

1718-8598 (numérique)

Découvrir la revue

\section{Citer cet article}

Zouaghi, R., Zertal, A., David, B. \& Guittonneau, S. (2007). Photocatalytic Degradation of Monolinuron and Linuron in an Aqueous Suspension of Titanium Dioxide Under Simulated Solar Irradiation. Revue des sciences de l'eau / Journal of Water Science, 20(2), 163-172. https://doi.org/10.7202/015810ar

\section{Résumé de l'article}

La dégradation photocatalytique de deux herbicides, le monolinuron (MLN) et le linuron (LN), a été étudiée dans une suspension de $\mathrm{TiO}_{2}$ au contact de lumière solaire simulée. L'objectif de cette étude est de comparer leur photoréactivité et d'évaluer l'influence de différents paramètres tels que la concentration initiale en pesticide, la concentration en catalyseur et le flux photonique sur la cinétique de dégradation du monolinuron. L'étude comparative de la dégradation des deux herbicides a montré que les deux composés présentent une réactivité comparable avec le système $\mathrm{TiO}_{2}$ /lumière simulée. Dans les conditions opératoires de cette étude, la dégradation photocatalytique du LN et du MLN suit une cinétique de pseudo ordre 1. La pseudo-constante $\mathrm{k}_{\mathrm{obs}}$ est inversement proportionnelle à la concentration initiale en pesticide et peut être décrite par une équation de Langmuir-Hinshelwood. L'étude de l'influence de la concentration en $\mathrm{TiO}_{2}$ a permis de montrer que la cinétique de dégradation du MLN augmente avec la dose de catalyseur, mais un surdosage n'est pas nécessaire pour augmenter l'efficacité du procédé. Cette étude a permis également de montrer que la pseudo-constante d'ordre 1 de dégradation du MLN augmente linéairement avec le flux lumineux jusqu'à $580 \mathrm{~W} \mathrm{~m}^{-2}$ puis décroît. Dans ces conditions, la recombinaison des électrons trous est favorisée. Enfin, la cinétique de dégradation du MLN en fonction du $\mathrm{pH}$ passe par un optimum de $\mathrm{pH}$ proche du $\mathrm{pH}$ de point de charge nulle $(\mathrm{pH}=6)$. 


\title{
PHOTOCATALYTIC DEGRADATION OF MONOLINURON AND LINURON IN AN AQUEOUS SUSPENSION OF TITANIUM DIOXIDE UNDER SIMULATED SOLAR IRRADIATION
}

\author{
Dégradation photocatalytique du monolinuron et du linuron dans une suspension aqueuse de dioxide de titanium au \\ contact de lumière solaire simulée
}

\author{
Razika Zouaghia ${ }^{b}$, Abdennour Zertal, Bernard David ${ }^{b}$ and Sylvie Guittonneau ${ }^{b^{*}}$ \\ ${ }^{a}$ Laboratoire des Sciences et Technologie de l'Environnement, Université de Mentouri, Constantine, Algérie \\ ${ }^{b}$ Laboratoire de Chimie Moléculaire et Environnement, Université de Savoie, Savoie Technolac, 73376 Le Bourget du Lac, France
}

Reçu le 30 octobre 2005, accepté le 18 september 2006

\section{ABSTRACT}

The photocatalytic degradation of two phenylurea herbicides, monolinuron (MLN) and linuron (LN), was investigated in an aqueous suspension of $\mathrm{TiO}_{2}$ using simulated solar irradiation. The objective of the study was to compare their photocatalytic reactivity and to assess the influence of various parameters such as initial pesticide concentration, catalyst concentration and photonic flux on the photocatalytic degradation rate of MLN and LN. A comparative study of the photocatalytic degradation kinetics of both herbicides showed that these two compounds have a comparable reactivity with $\mathrm{TiO}_{2} /$ simulated sun light. Under the operating conditions of this study, the photocatalytic degradation of MLN and LN followed pseudo first-order decay kinetics. The $\mathrm{k}_{\mathrm{obs}}$ values indicated an inverse dependence on the initial herbicide concentration and were fitted to the Langmuir-Hinshelwood equation. Photocatalytic degradation rates increased with $\mathrm{TiO}_{2}$ dosage, but overdoses did not necessarily increase the photocatalytic efficiency. The degradation rate of MLN increased with radiant flux until an optimum at $580 \mathrm{~W} \mathrm{~m}^{-2}$ was reached and then decreased. Under these conditions, an electron-hole recombination was favored. Finally, the photocatalytic degradation rate depended on $\mathrm{pH}$, where an optimum was found at a $\mathrm{pH}$ value close to the $\mathrm{pH}$ of the point of zero charge $(\mathrm{pH}=6)$.

Keywords: Linuron; Monolinuron; phenyl urea herbicides; photocatalysis; titanium dioxide.

\section{RÉSUMÉ}

La dégradation photocatalytique de deux herbicides, le monolinuron (MLN) et le linuron (LN), a été étudiée dans une suspension de $\mathrm{TiO}_{2}$ au contact de lumière solaire simulée. Lobjectif de cette étude est de comparer leur photoréactivité et d'évaluer l'influence de différents paramètres tels que la concentration initiale en pesticide, la concentration en catalyseur et le flux photonique sur la cinétique de dégradation du monolinuron. L'étude comparative de la dégradation des deux herbicides a montré que les deux composés présentent une réactivité comparable avec le système $\mathrm{TiO}_{2}$ /lumière simulée.

\footnotetext{
*Auteur pour correspondance :

Téléphone: (33)4 79758606

Télécopieur: (33) 479758674

Courriel : Sylvie.Guittonneau@univ-savoie.fr

Razika_zouaghi@yahoo.fr
} 
Dans les conditions opératoires de cette étude, la dégradation photocatalytique du LN et du MLN suit une cinétique de pseudo ordre 1. La pseudo-constante $\mathrm{k}_{\text {obs }}$ est inversement proportionnelle à la concentration initiale en pesticide et peut être décrite par une équation de Langmuir-Hinshelwood. L'étude de l'influence de la concentration en $\mathrm{TiO}_{2}$ a permis de montrer que la cinétique de dégradation du MLN augmente avec la dose de catalyseur, mais un surdosage n'est pas nécessaire pour augmenter l'efficacité du procédé. Cette étude a permis également de montrer que la pseudo-constante d'ordre 1 de dégradation du MLN augmente linéairement avec le flux lumineux jusqu'à $580 \mathrm{~W} \mathrm{~m}^{-2}$ puis décroît. Dans ces conditions, la recombinaison des électrons trous est favorisée. Enfin, la cinétique de dégradation du MLN en fonction du $\mathrm{pH}$ passe par un optimum de $\mathrm{pH}$ proche $\mathrm{du} \mathrm{pH}$ de point de charge nulle $(\mathrm{pH}=6)$.

\section{Mots clés : Linuron; Monolinuron; herbicides phényl urées; photocatalyse;oxyde de titane}

\section{INTRODUCTION}

In the last few decades, considerable attention has been given to the toxic and persistent pollutants coming from industrial and agricultural human activities. The application of photochemistry to environmental remediation and treatment has also been an active area of research and heterogeneous photocatalysis using $\mathrm{UV} / \mathrm{TiO}_{2}$ system has often been proposed to eliminate these pollutants (BAHNEMANN et al., 1994; CUNNINGHAM and SRIJARANAI, 1994; HERRMANN, 1999; MARINAS et al., 2001; OLLIS and EL-EKABI, 1993). Titanium dioxide is widely used as photocatalyst because it is photochemically stable, non-toxic and low cost (AUGUGLIARO et al., 1995; TAPOLOV et al., 2000). This process is based on the generation of reactive species (electron/ positive hole pairs) upon absorption of UV light $(\lambda<368 \mathrm{~nm})$ by the photocatalyst. In the presence of oxygen, the electron may induce reduction and leads to the formation of superoxide anions. Positive holes oxidize adsorbed organic substrates or react with water leading to the formation of hydroxyl radicals. These radicals are well known to be strong oxidant agents (the reduction potential is as high as $2.8 \mathrm{~V} / \mathrm{HSE}$ ) and react efficiently without any selectivity with most organic substrates (D'OLIVEIRA et al., 1990; OKAMOTO et al., 1985; OLLIS et al., 1989).

Phenylurea herbicides were introduced in the 1950's and their use has considerably increased. Monolinuron (MLN) and Linuron (LN) (Figure 1) are widely used in pre- and postemergence for treatment of both crop and non-crop cultures. These herbicides are moderately persistent in soils, with a field half-life of approximately 30 to 150 days and are slightly to

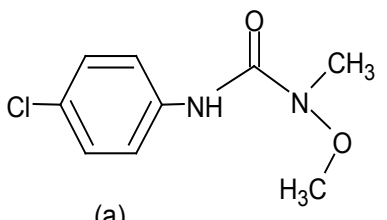

(a)

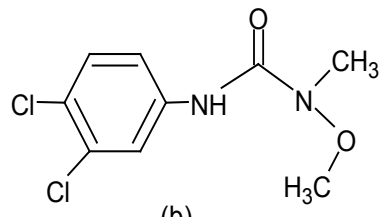

(b)
Figure 1. Chemical structure of (a) monolinuron (MLN) and (b) linuron (LN).

Formule chimique du (a) monolinuron (MLN) et (b) linuron $(L N)$.

moderately soluble in water $\left(\mathrm{s}=735\right.$ and $81 \mathrm{mg} \mathrm{L}^{-1}$ at $25^{\circ} \mathrm{C}$ for MLN and LN respectively) (TOMLIN, 2000). Consequently, MLN and LN can give rise to important residues in soil and in water.

The aim of the present work was to study the photocatalytic degradation of $\mathrm{LN}$ and MLN in presence of $\mathrm{TiO}_{2}$ in aqueous solution using simulated solar irradiation. The effect of various parameters, such as herbicide concentration, photonic flux, mass of catalyst and $\mathrm{pH}$ on the decay of MLN, was investigated. These herbicides were the subject of direct photolysis but there are no published papers concerning their photocatalytic transformation.

\section{MATERIALS AND METHODS}

\subsection{Reactants}

All reagents were of the purest grade commercially available and were used without further purification. Monolinuron (3-(4-chlorophenyl)-1-methoxy-1-methylurea, 99\%) was Riedel- de Haën and linuron (3-(3,4-dichlorophenyl)-1methoxy-1-methylurea), 98\%) was from Chem. Service. Titanium dioxide Degussa P25 was mostly in the anatase form (70\% anatase, 30\% rutile) with an average particle size of $30 \mathrm{~nm}$ and BET surface area of $50 \mathrm{~m}^{2} \mathrm{~g}^{-1}$. Acetonitrile, HPLC grade product, was purchased from Merck. Current reagents such as $\mathrm{NaHCO}_{3}$ and $\mathrm{Na}_{2} \mathrm{CO}_{3}$ were analytic grades (Merck). Water was purified by Milli-Q system (Millipore) and controlled by its resistivity $\left(18 \mathrm{M} \Omega \mathrm{cm}^{-1}\right)$.

\subsection{Photocatalytic experiments}

Suspensions of $\mathrm{TiO}_{2}\left(0-1.5 \mathrm{~g} \mathrm{~L}^{-1}\right)$ in aqueous solutions of MLN or LN (0.8-8 $\left.\mathrm{mg} \mathrm{L}^{-1}\right)$ were irradiated in a CPS+ ATLAS Suntest simulator, equipped with a Xenon lamp (irradiance between 250 and $765 \mathrm{Wm}^{-2}$ ) with a cut-off at $\lambda=290 \mathrm{~nm}$. The reactor was an open water-jacketed cylindrical vessel (Figure 2). Experiments were carried out under aerated 


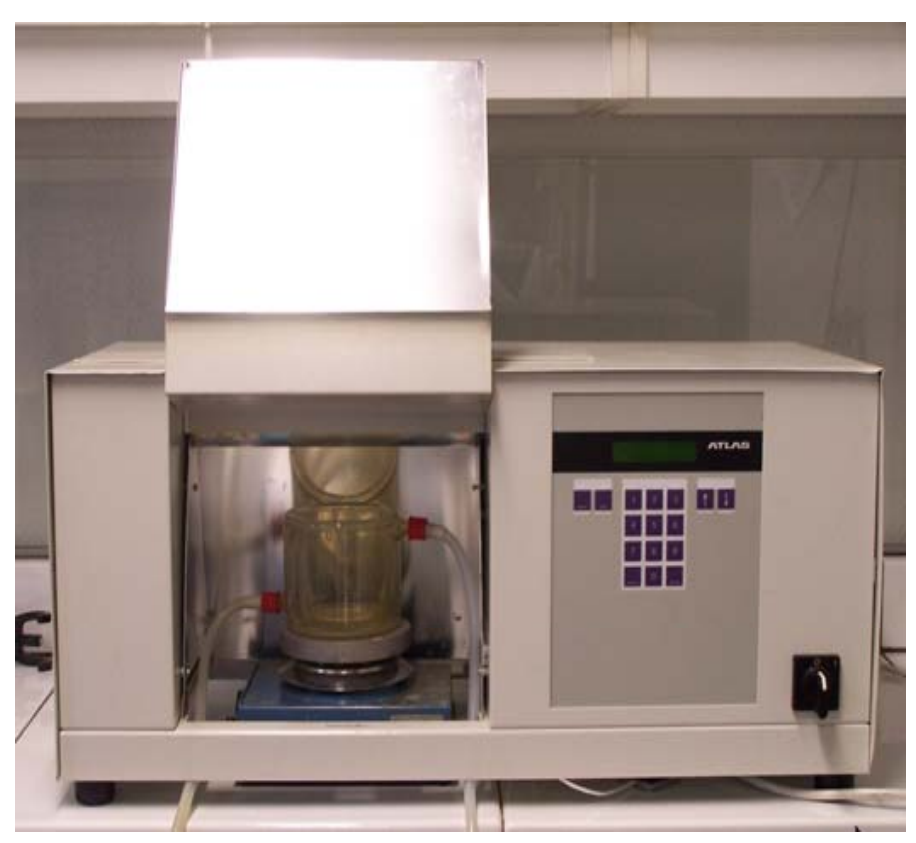

Figure 2. CPS+ ATLAS Suntest simulator.

Simulateur solaire CPS+ ATLAS Suntest.

conditions $\left(\left[\mathrm{O}_{2}\right]=7.4 \mathrm{mg} \mathrm{L}^{-1}\right)$ at a temperature of the irradiated solutions maintained at $17 \pm 3^{\circ} \mathrm{C}$. In all experiments, the total irradiated solution volume was $250 \mathrm{~mL}$ with a path length of $4 \mathrm{~cm} . \mathrm{TiO}_{2}$ was maintained in suspension before and during irradiation by magnetic stirring. Aliquots of suspensions were sampled at the end of the adsorption for a period of one hour and during irradiation at selected time intervals. Samples were filtered through hydrophilic polypropylene filters $(0.45 \mu \mathrm{m})$ to remove $\mathrm{TiO}_{2}$ particles prior to HPLC analysis.

\subsection{Analysis}

UV-visible spectra were recorded on Unicam HELIOS $\alpha$ double beam spectrophotometer. The disappearance of substrates and formation of products were monitored by HPLC on a WATERS chromatograph equipped with two pumps (WATERS 515) and a photodiode array detector (WATERS 996). The column was an Interchim UP3 $^{*} 12 \mathrm{QK}(3 \mu \mathrm{m}, 125 \mathrm{~mm} \times 4 \mathrm{~mm})$. The eluant was a mixture of 40/60 (V/V) acetonitrile-water $+1 \%$ acetic acid for MLNand50/50 (V/V) acetonitrile-waterforLN, with aflow rate of $0.7 \mathrm{~mL} \mathrm{~min}^{-1}$ and detection wavelength at $244 \mathrm{~nm}$. Chloride ion concentrations were determined by ionic chromatography. A cartridge glass IC column (Metrosep Anion Dual 1: $150 \times 3.0 \mathrm{~mm}$ ) was used. The eluant was a mixture of $\mathrm{Na}_{2} \mathrm{CO}_{3}\left(2.5 \mathrm{mmol} \mathrm{L}^{-1}\right)$ and $\mathrm{NaHCO}_{3}\left(2.4 \mathrm{mmol} \mathrm{L}^{-1}\right)$. Under these conditions, retention times of LN, MLN and chloride ions were 10.3, 10.5 and 5.5 minutes respectively.

\section{RESULTS AND DISCUSSION}

\subsection{UV spectra}

The UV absorption spectra of monolinuron and linuron in aqueous solution are given in Figure 3. These two herbicides have similar absorption spectra with a maximum absorption band located at $243 \mathrm{~nm}$ and $246 \mathrm{~nm}$, and with a molar absorption coefficient of $17,500 \pm 50 \mathrm{~L} \mathrm{~mol}^{-1} \mathrm{~cm}^{-1}$ and $16,500 \pm 50 \mathrm{~L} \mathrm{~mol}^{-1} \mathrm{~cm}^{-1}$ for MLN and LN respectively. The

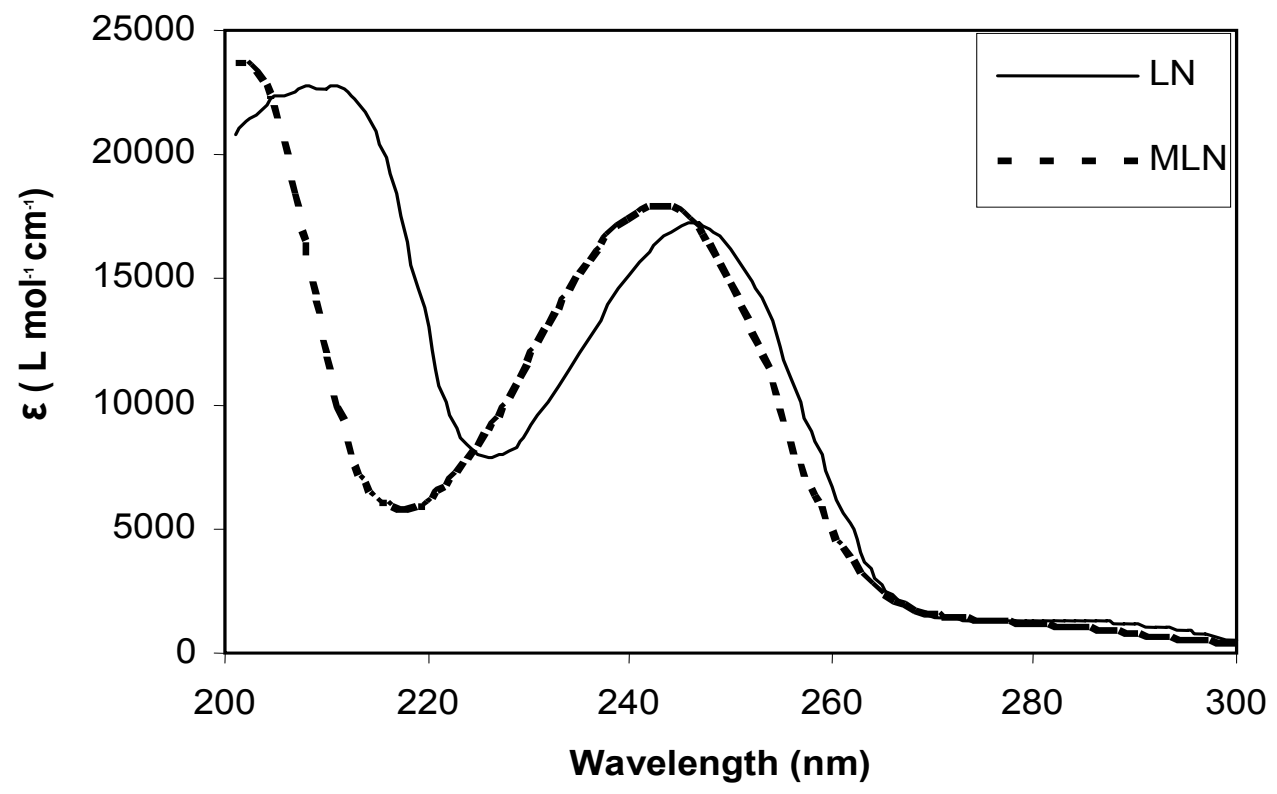

Figure 3. UV spectra of linuron and monolinuron. Spectres $U V d u$ linuron et du monolinuron. 
weak bathochromic shift $(\Delta \lambda=3 \mathrm{~nm})$ and hypochrom effect $\left(\Delta \varepsilon=1000 \mathrm{~L} \mathrm{~mol}^{-1} \mathrm{~cm}^{-1}\right)$ are due to the presence of a second chlorine atom on the benzene ring for $\mathrm{LN}$. For both pesticides, a shoulder with a maximum around $280 \mathrm{~nm}$ is also observed with a molar absorption coefficient of $1,200 \mathrm{~L} \mathrm{~mol}^{-1} \mathrm{~cm}^{-1}$.

\subsection{Direct photolysis and photocatalysis}

In the absence of $\mathrm{TiO}_{2}$, no significant decrease in the concentration of both herbicides was observed under simulated solar irradiation for about two hours (Figure 4). In this case, the amount of pesticide removed is less than $8 \%$ for an incident photonic flux of $250 \mathrm{~W} \mathrm{~m}^{-2}$. The very low molar absorption coefficient for both molecules above $300 \mathrm{~nm}$ associated with their weak quantum yield, result in a good photostability of these pesticides under sunlight irradiation, which implies that these compounds would be removed very slowly by direct photolysis. In presence of $\mathrm{TiO}_{2}$, amounts of MLN and LN adsorbed over photocatalyst in the dark were less than 5\%, thus degradation of these herbicides is exclusively due to photocatalytic processes via the formation of hydroxyl radicals generated at the surface of the semiconductor (NARGIELLO and HERZ, 1993; OLLIS et al., 1989).
For our experimental conditions ([Herbicide] $=210^{-5} \mathrm{~mol} \mathrm{~L}^{-1} ; \quad\left[\mathrm{TiO}_{2}\right]=0.2 \mathrm{~g} \mathrm{~L}^{-1} ;$ photonic flux $\mathrm{P}=250 \mathrm{~W} \mathrm{~m}^{-2}$ ), data are in a good agreement with a pseudo-first-order reaction, as evidenced by plotting $\ln \left(\mathrm{C}_{\mathrm{o}} / \mathrm{C}\right)$ versus irradiation time (insert in Figure 4). The apparent rate constants calculated for monolinuron and linuron irrradiated in separate solutions are $0.081 \mathrm{~min}^{-1}$ and $0.082 \mathrm{~min}^{-1}$ with a half-life time of about 8.5 min indicating that MLN and LN have a similar reactivity with $\mathrm{TiO}_{2} /$ Simulated sunlight. The substitution of the benzene ring with one or two $\mathrm{Cl}$ atoms does not affect the photocatalytic reactivity of these pesticides.

In order to determine whether MLN and LN were completely mineralized, the concentration of chloride ions and TOC (Total Organic Carbon) was monitored at different irradiation times.

As shown in Figures $5 \mathrm{a}$ and $5 \mathrm{~b}$, total dechlorination of both pesticides is obtained after the corresponding time of illumination required for the total disappearance of the initial substrate. On the other hand, TOC removal is only $25 \%$ for $\mathrm{LN}$ and MLN. This means that mineralization of both substrates

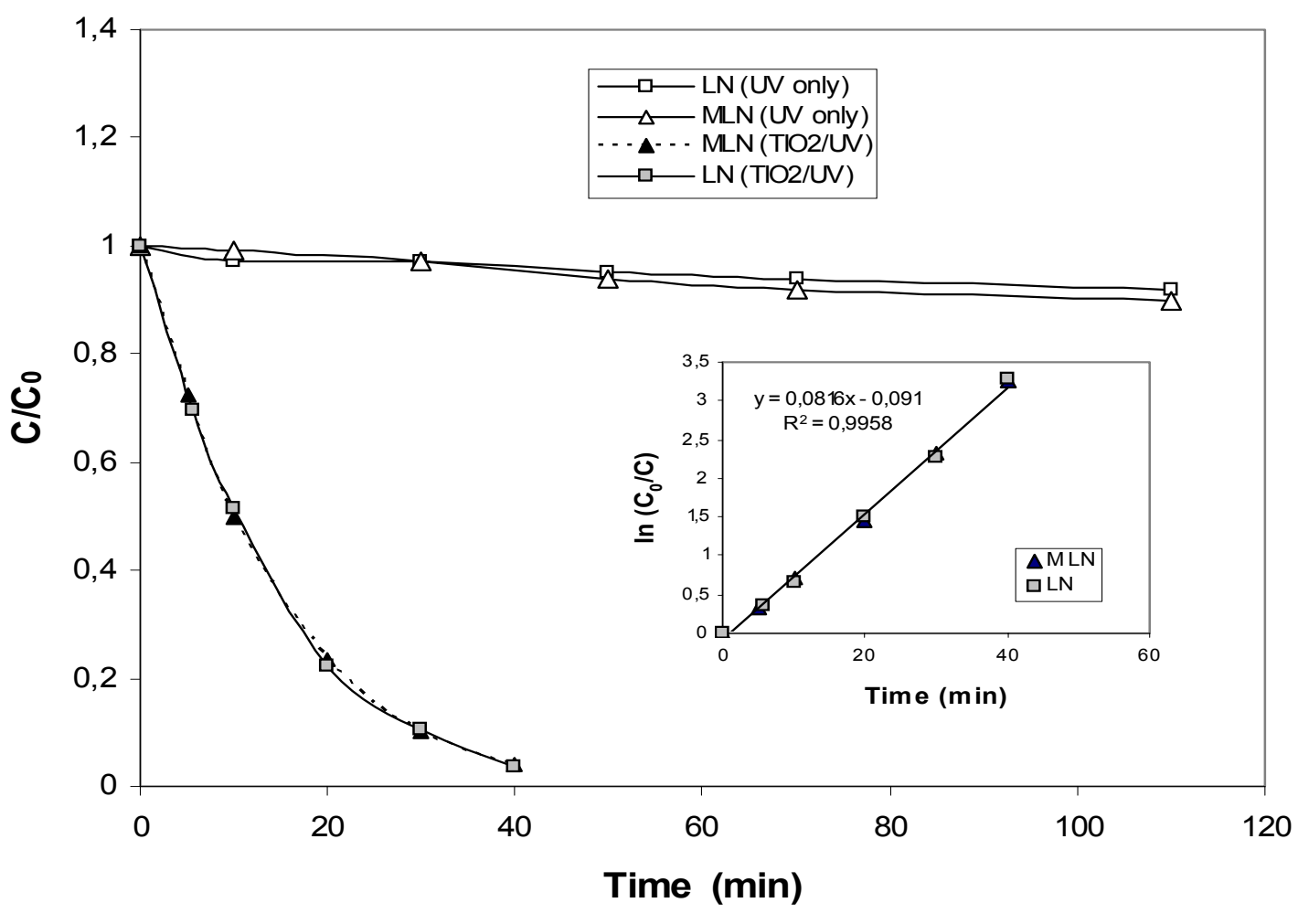

Figure 4. Kinetics of the disappearance of MLN and $\mathrm{LN}\left(\mathrm{C}_{\mathrm{o}}=2 \cdot 10^{-5} \mathrm{~mol} \mathrm{~L}^{-1}\right)$ in the presence of $0.2 \mathrm{~g} \mathrm{~L}^{-1}$ of $\mathrm{TiO}_{2}$ at $250 \mathrm{~W} \mathrm{~m}^{-2}$ (insert: $\ln \left(\mathrm{Ct} / \mathrm{C}_{0}\right)=\mathbf{f}($ time $\left.)\right)$.

Cinétique de disparition du MLN et $L N\left(C_{o}=2 \bullet 10^{-5} \mathrm{~mol} \mathrm{~L}^{-1}\right)$ en présence de $0,2 \mathrm{~g} \mathrm{~L}^{-1}$ de $\mathrm{TiO}_{2}$ à $250 \mathrm{Wm}^{-2}$ (insertion : $\ln \left(C t / C_{0}\right)=f($ temps $)$ ). 


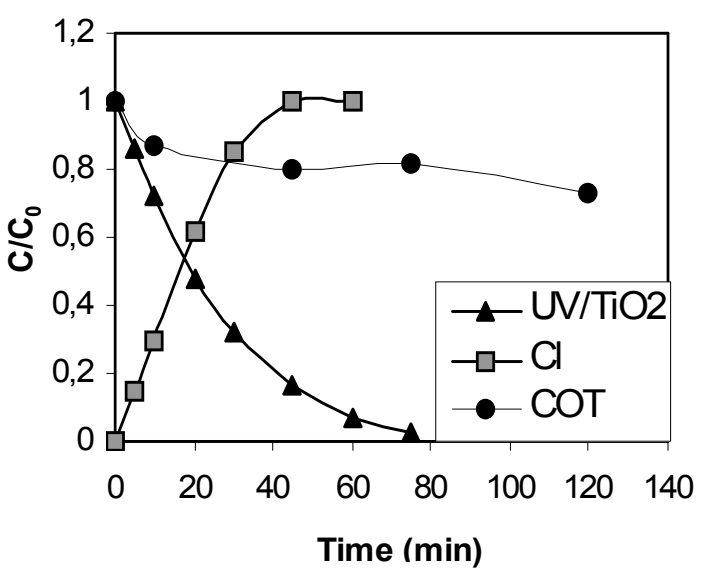

a)

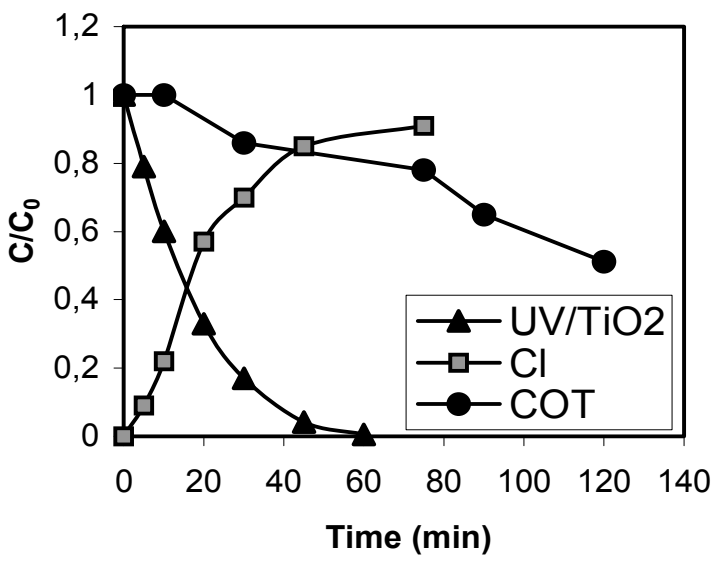

b)

Figure 5. Kinetics of the disappearance of the two herbicides, appearance of chloride ions and evolution of the TOC $\left(\mathrm{C}_{0}=2 \cdot 10^{-5} \mathrm{~mol} \mathrm{~L}^{-1},\left[\mathrm{TiO}_{2}\right]=0.2 \mathrm{~g} \mathrm{~L}^{-1}, \mathrm{P}=250 \mathrm{~W} \mathrm{~m}^{-2}\right)$ - (a) linuron, (b) monolinuron.

Cinétique de disparition des deux herbicides, apparition des ions chlorure et évolution du $\operatorname{COT}\left(C_{0}=2 \cdot 10^{-5} \mathrm{~mol} \mathrm{~L}^{-1},\left[\mathrm{TiO}_{2}\right]=0,2 \mathrm{~g} \mathrm{~L}^{-1}, \mathrm{P}=250 \mathrm{Wm}^{-2}\right)$ - (a) linuron, (b) monolinuron.

is slow in spite of their photodegradation. Chromatographic analysis of MLN solution $\left(\mathrm{C}_{\mathrm{o}}=3.7 \cdot 10^{-5} \mathrm{~mol} \mathrm{~L}^{-1}\right)$, irradiated during $45 \mathrm{~min}$, in the presence of $0.2 \mathrm{~g} \mathrm{~L}^{-1}$ of $\mathrm{TiO}_{2}$, shows the formation of two major photoproducts $\left(\mathrm{P}_{1}\right.$ and $\left.\mathrm{P}_{2}\right)$ (Figure 6). UV-visible spectra analysis of these products indicates that they absorb mainly at the same wavelength range as MLN, confirming that primary $\mathrm{OH}$ radical attack does not destroy the aromatic ring. The kinetics of formation and disappearance of $\mathrm{P}_{1}$ and $\mathrm{P}_{2}$ show that they are primary products.

Identification of these compounds was not investigated, but according to (i) our kinetic results for chloride ion formation and TOC removal and (ii) the degradation scheme of similar phenyl urea herbicides such as metobromuron (AMINE-KHODJA et al., 2005) or monuron (PRAMAURO and VINCENTI, 1993) reported in the literature, $\mathrm{P}_{1}$ and $\mathrm{P}_{2}$ could result from the simultaneous attack of radical species on two positions of the initial molecule with:

Hydroxylation of the aromatic ring by substitution of $\mathrm{Cl}$ atom.

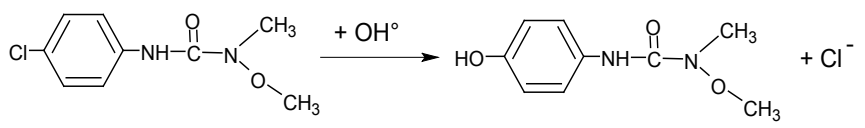

An attack of the alkyl urea group leading to the partial mineralization of initial substrate.

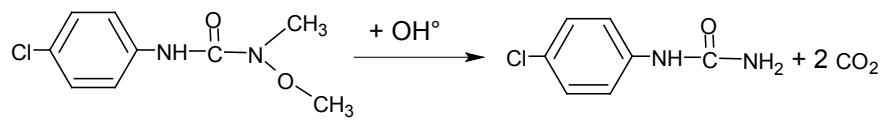

The kinetic behaviour of these derivatives (Figure 6) clearly confirms that these aromatic compounds undergo further transformation, probably into non-aromatic products which cannot be detected by HPLC analysis under the experimental conditions used in this study. Total mineralization of these intermediates will require a long irradiation time since residual TOC still remains after two hours of irradiation.

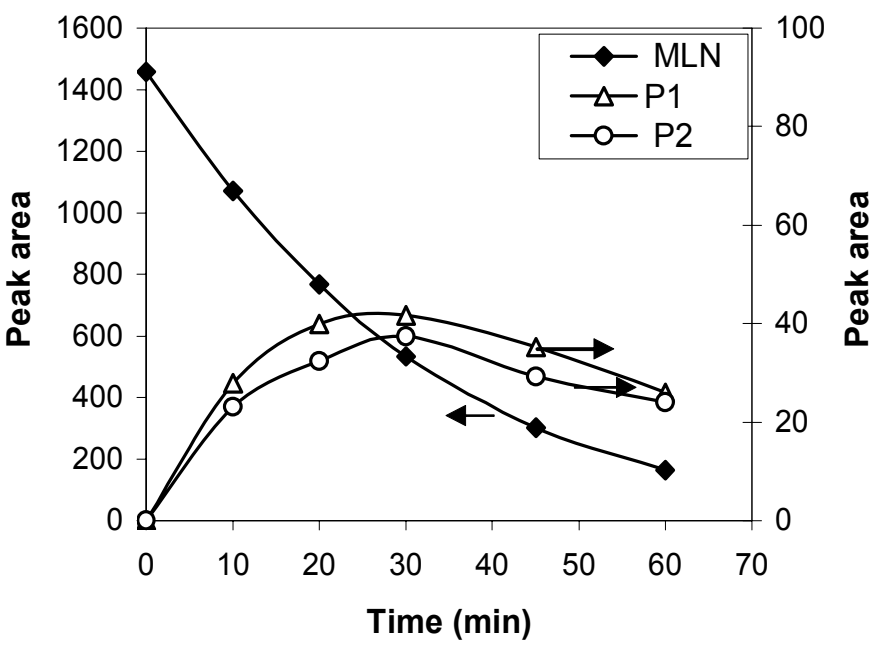

Figure 6. Kinetics of the disappearance of MLN and formation of intermediates $\left([\mathrm{MLN}]=3.7 \cdot 10^{-5} \mathrm{~mol} \mathrm{~L}^{-1},\left[\mathrm{TiO}_{2}\right]=\right.$ $0.2 \mathrm{~g} \mathrm{~L}^{-1}, \mathrm{P}=250 \mathrm{~W} \mathrm{~m}^{-2}$ ).

Cinétique de disparition du MLN et formation des intermédiaires $\left([M L N]=3,7 \cdot 10^{-5} \mathrm{~mol} \mathrm{~L}^{-1},\left[\mathrm{TiO}_{2}\right]=\right.$ $0,2 \mathrm{gL}^{-1}, P=250 \mathrm{Wm}^{-2}$ ). 


\subsection{Effect of various parameters on monolinuron photocatalytic} degradation

Initial herbicide, $\mathrm{TiO}_{2}$ concentrations and photonic flux are important parameters which can affect photocatalytic degradation rates. The effect of these three parameters has been studied at natural $\mathrm{pH}(\mathrm{pH}=5)$, on the photocatalytic degradation of monolinuron (MLN) chosen as the pesticide. For all experiment sets, the data found for the degradation of MLN are in good agreement with a pseudo-first-order reaction with respect to concentrations in the experimental range $\left(0.98<\mathrm{r}^{2}<0.99\right)$.

$$
\mathrm{r}_{\mathrm{MLN}}=-\frac{\mathrm{d}[\mathrm{MLN}]}{\mathrm{dt}}=\mathrm{k}_{\mathrm{obs}}[\mathrm{MLN}]
$$

\subsubsection{Effect of $\mathrm{TiO}_{2}$ concentration}

Figure 7 shows the influence of $\mathrm{TiO}_{2}$ concentration $\left(\left[\mathrm{TiO}_{2}\right]=0.1\right.$ to $\left.1.5 \mathrm{~g} \mathrm{~L}^{-1}\right)$ on the degradation rate of MLN at $4 \mathrm{mg} \mathrm{L}^{-1}$ and for a photonic flux of $250 \mathrm{~W} \mathrm{~m}^{-2}$. As expected, the apparent rate constant $\left(\mathrm{k}_{\text {obs }}\right)$ was found to increase with the increasing concentration of semiconductor. This enhancement is due to the increase of the number of active sites with the $\mathrm{TiO}_{2}$ concentration. However, $\mathrm{k}_{\mathrm{obs}}$ tends to a limit that corresponds to the total absorption of the photonic flux by the catalyst as illustrated in Figure 7 (average absorbance between 290 and $400 \mathrm{~nm}$ of the $\mathrm{TiO}_{2}$ suspension for $4 \mathrm{~cm}$ path length versus $\mathrm{k}_{\mathrm{obs}}$. For our experimental conditions, this limit seems to be reached at $1 \mathrm{~g} \mathrm{~L}^{-1}$ for which $99 \%$ of the light is absorbed. Above this concentration, a plateau is observed as it is mentioned by several authors (INEL and OKTE, 1996; Le CAMPION et al., 1999; PARRA et al., 2002; WONG and CHU, 2003). Figure 7 also points out that at low $\mathrm{TiO}_{2}$ concentration $\left(<0.1 \mathrm{~g} \mathrm{~L}^{-1}\right)$ or weak absorption, the degradation of monolinuron occurs at very low rate.

\subsubsection{Effect of herbicide concentration}

The effect of the monolinuron concentration has been studied in a range between 0.8 to $8 \mathrm{mg} \mathrm{L}^{-1}$ for a constant $\mathrm{TiO}_{2}$ dosage $\left(\left[\mathrm{TiO}_{2}\right]=0.2 \mathrm{~g} \mathrm{~L}^{-1}\right)$ and a constant photonic flux $\left(\mathrm{P}=250 \mathrm{~W} \mathrm{~m}^{-2}\right)$. Figure 8 shows that the apparent firstorder rate constant $\mathrm{k}_{\mathrm{obs}}$ decreases with the increasing of the initial concentration of MLN. This can be explained by the competition of photoproducts with substrate for the adsorption on the active sites of the $\mathrm{TiO}_{2}$ surface (OLLIS et al., 1989; PRAMAURO and VINCENTI, 1993).

In the last few decades, the Langmuir-Hinshelwood expression has been successfully used to describe the dependence of the reaction rate $r_{M L N}$ on the initial concentration of the

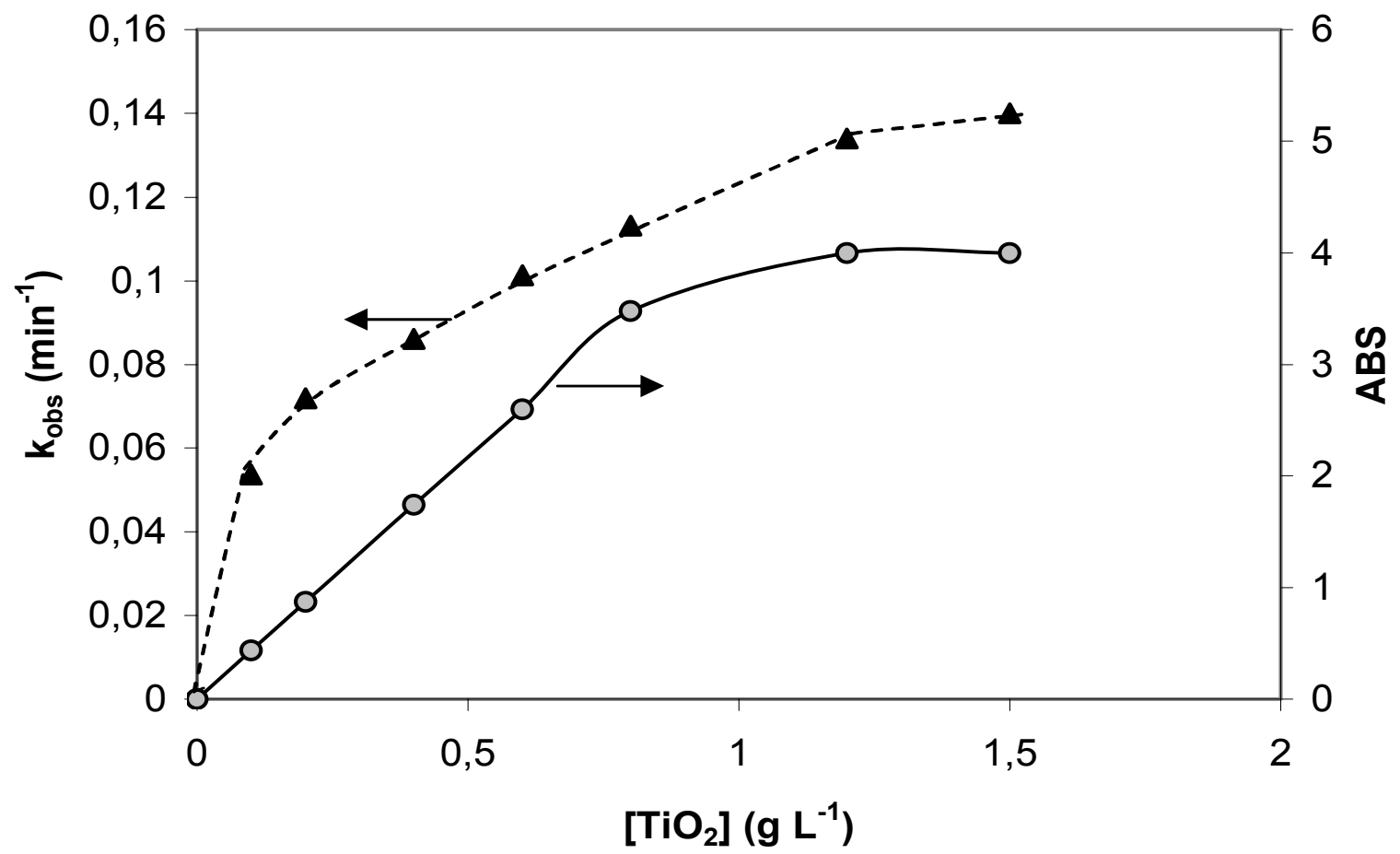

Figure 7. Effect of $\mathrm{TiO}_{2}$ concentration on the pseudo-first-order rate constant. Influence de la concentration en $\mathrm{TiO}_{2}$ sur la pseudo-constante d'ordre 1. 


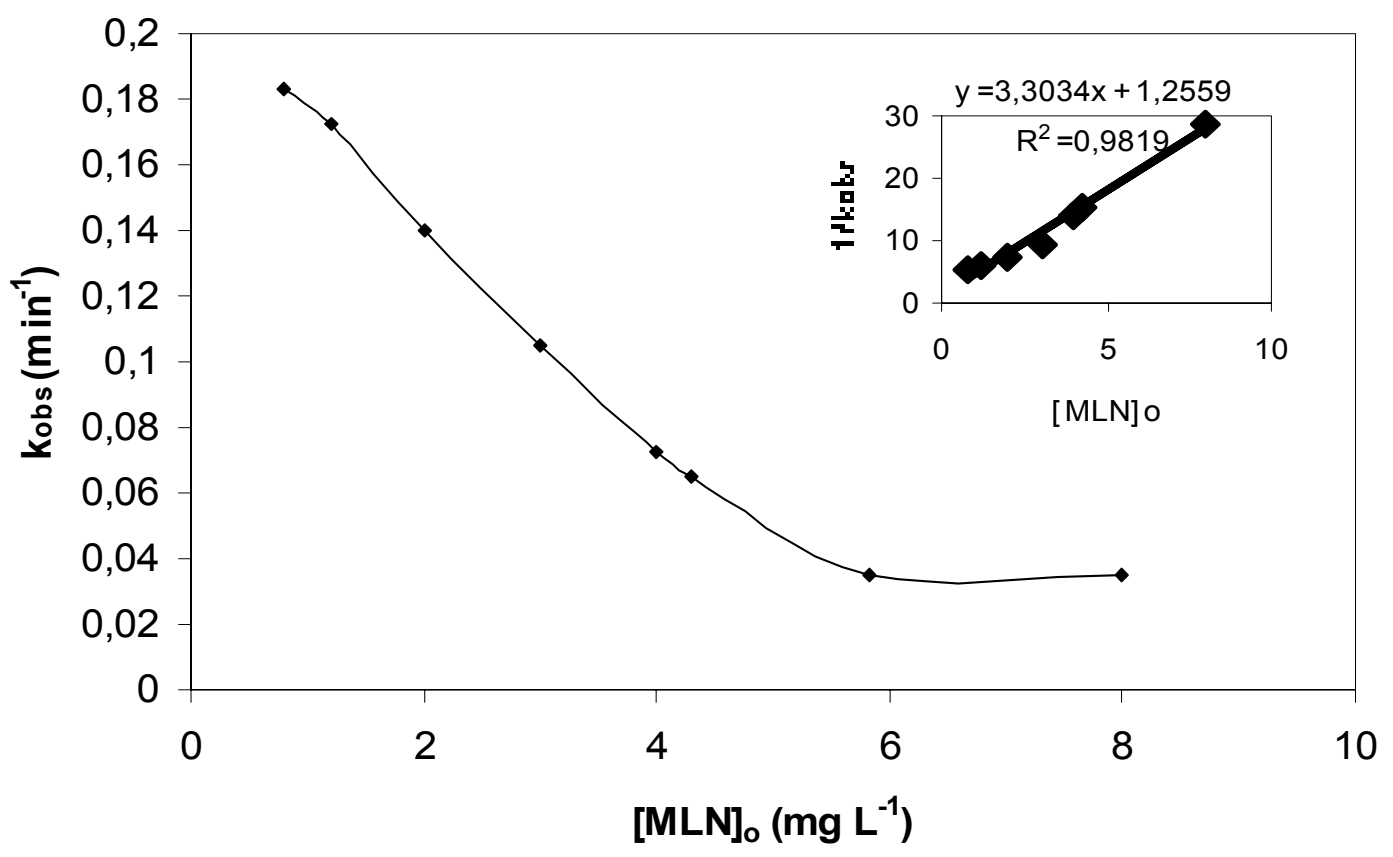

Figure 8. Effect of initial MLN concentration on the pseudo-first-order rate constant. Influence de la concentration initiale en MLN sur la pseudo-constante d'ordre 1.

organic substrate $[\mathrm{MLN}]_{\mathrm{o}}$ for heterogeneous photocatalytic degradation (HEREDIA et al., 2001):

$$
\mathrm{r}_{\mathrm{MLN}}=-\frac{\mathrm{d}[\mathrm{MLN}]}{\mathrm{dt}}=\mathrm{k}_{\mathrm{obs}}[\mathrm{MLN}]=\frac{\mathrm{kK}_{\mathrm{MLN}}[\mathrm{MLN}]}{1+\mathrm{K}_{\mathrm{MLN}}[\mathrm{MLN}]_{\mathrm{o}}}
$$

where: $\mathrm{K}_{\mathrm{MLN}}$ is the Langmuir-Hinshelwood adsorption equilibrium constant of monolinuron and $\mathrm{k}$ is the rate constant at the surface reaction. A plot of $1 /$ kobs $v$ s. initial monolinuron concentration $[\mathrm{MLN}]_{\mathrm{o}}$ gave a straight line (Figure 8) indicating that the kinetics fit with a LangmuirHinshelwood equation :

$$
\frac{1}{\mathrm{k}_{\mathrm{obs}}}=\frac{1}{\mathrm{kK}_{\mathrm{MLN}}}+\frac{[\mathrm{MLN}]_{\mathrm{o}}}{\mathrm{k}}
$$

From the intercept and the slope, $\mathrm{k}$ and $\mathrm{K}_{\mathrm{MLN}}$ can be easily calculated. The results obtained are $\mathrm{k}=0.30 \mathrm{mg} \mathrm{L}^{-1} \mathrm{~min}^{-1}\left(1.4 \cdot 10^{-6} \mathrm{~mol} \mathrm{~L}^{-1} \mathrm{~min}^{-1}\right)$ and $\mathrm{K}_{\mathrm{MLN}}=2.6 \mathrm{~L} \mathrm{mg}^{-1}\left(5.6 \cdot 10^{5} \mathrm{~L} \mathrm{~mol}^{-1}\right)$. The determination of these constants for the photocatalytic transformation of monolinuron has no absolute meaning because they depend on various parameters such as $\mathrm{TiO}_{2}$ concentration, $\mathrm{pH}$, photonic flux, etc. However, the good correlation obtained from the plot $1 / \mathrm{k}_{\mathrm{obs}} v$ s. initial monolinuron concentration $[\mathrm{MLN}]_{\mathrm{o}}$ indicates that the photocatalytic degradation of MLN occurred mainly at the surface of the semiconductor. As a consequence, the kinetics depend on the equilibrium of sorption / desorption of the pesticide, and thus on its initial concentration.

\subsubsection{Effect of radiant flux}

The incident flux, which is of great importance in the photocatalytic process, has been the subject of many studies. OLLIS et al. (1989), D'OLIVEIRA et al. (1990) and AlSAYYED et al. (1991) reported that at low intensity levels of illumination, the degradation rate is of first-order in intensity. However, at high intensity, the reaction rate increases with the square root of the intensity level. INEL and OKTE (1996) also found a similar rate shift from first order to half order. The initial degradation rate of 4-nitrophenol versus radiant flux was also investigated in the range of $0-180 \mathrm{~W} \mathrm{~m}^{-2}$ (CHEN and RAY, 1998), where the effect was correlated by: $\mathrm{k} \propto \mathrm{P}^{0.84}$. This was explained by the fact that at low levels of intensity the degradation rate is neither catalyst dependent nor mass transfer dominated.

For our study, the effect of the radiant flux on the photocatalytic degradation of MLN is shown in Figure 9 for a range varying from 250 to $765 \mathrm{Wm}^{-2}\left[\mathrm{TiO}_{2}\right]=0.2 \mathrm{~g} \mathrm{~L}^{-1}$, $\left.[\mathrm{MLN}]_{\mathrm{o}}=4 \mathrm{mg} \mathrm{L}^{-1}\right)$. It can be noted that the pseudo-rate constant passes through a maximum with an optimum at $\mathrm{P}_{\max }=580 \mathrm{~W} \mathrm{~m}^{-2}$. At low fluxes $\left(\mathrm{P}<580 \mathrm{~W} \mathrm{~m}^{-2}\right)$, the reaction rate is proportional to the radiant flux, indicating that the process works in a good photocatalytic regime: the incident photons are efficiently converted into actives species, corresponding to the degradation mechanism described above 


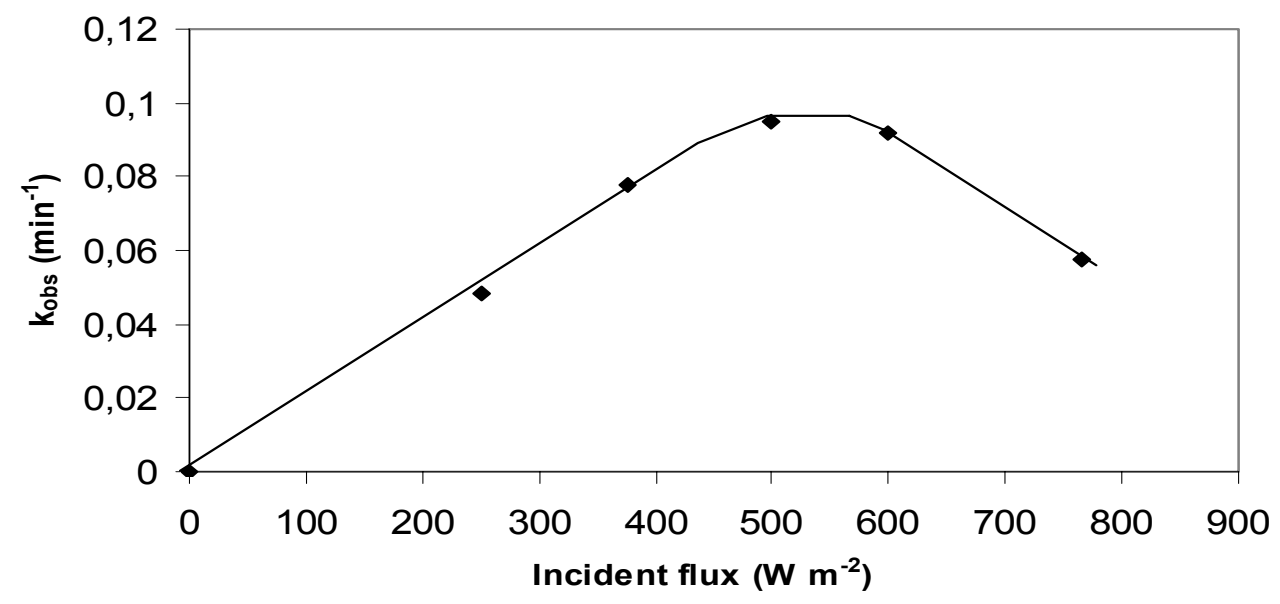

Figure 9. Effect of radiant flux on the pseudo-first-order rate constant. Influence du flux lumineux sur la pseudo-constante d'ordre 1.

(HERRMANN, 1999; VULLIET et al., 2003). At high fluxes, the rate decreases with the increase of radiant flux, indicating an increase of the recombination of photoproduced charges relative to the oxidation of substrate at high intensities, as has been reported elsewhere (Al-SAYYED et al., 1991; D'OLIVEIRA et al., 1990; HERRMANN, 1999; VINCZE and KEMP, 1990):

$$
\begin{aligned}
& \mathrm{TiO}_{2} \stackrel{\mathrm{kv}}{\longrightarrow} \mathrm{e}_{\mathrm{CB}}^{-}+\mathrm{h}^{+}{ }_{\mathrm{VB}} \\
& \mathrm{e}_{\mathrm{CB}}^{-}+\mathrm{h}^{+}{ }_{\mathrm{VB}} \longrightarrow \text { heat }
\end{aligned}
$$

\subsubsection{Effect of initial $p H$}

An important parameter that affects the rate of MLN degradation is the $\mathrm{pH}$ of the suspension. When substrates are dissolved in water, the effect consists in the change in:

- adsorption characteristics of molecules depending on their polarity and the charge of the $\mathrm{TiO}_{2}$ surface at different $\mathrm{pH}$ levels;

- predominance of radical species depending upon the hydroxyl or proton ion concentration.

It is well known that the point of zero charge (pzc) for $\mathrm{TiO}_{2}$ is at a pH between 5.6 and 6.4 and the surface coated with hydroxyl groups may add or release protons, as shown in the following equilibrium (CHEN and RAY, 1998; TERZIAN and SERPONE, 1995):

$$
\mathrm{Ti}^{\mathrm{IV}_{-}}-\mathrm{OH}_{2}^{+} \stackrel{-\mathrm{H}^{+}}{\rightleftharpoons} \mathrm{Ti}^{\mathrm{IV}}-\mathrm{OH} \stackrel{-\mathrm{H}^{+}}{\rightleftharpoons} \mathrm{Ti}^{\mathrm{IV}_{-}}-\mathrm{O}^{-}
$$

In this study, the $\mathrm{pH}$ was adjusted in acidic media with $\mathrm{HCl}$ or $\mathrm{HClO}_{4}$ and in basic media with $\mathrm{NaOH}$ or $\mathrm{NH}_{3}$. The effect of the addition of these bases and acids on the photocatalytic degradation rate of $\mathrm{MLN}\left(\mathrm{C}_{\mathrm{o}}=4 \mathrm{mg} \mathrm{L}^{-1} ; \mathrm{TiO}_{2}=0.2 \mathrm{~g} \mathrm{~L}^{-1}\right.$; $\mathrm{P}=250 \mathrm{~W} \mathrm{~m}^{-2}$ ) is illustrated in Figure 10. Results indicate that $\mathrm{pH}$ value has a significant effect at both low and high $\mathrm{pH}$ :

- At $\mathrm{pH}<6.3$, the photocatalytic degradation rate of MLN depends on the acid used. When $\mathrm{HCl}$ is used, the degradation rate decreases with $\mathrm{pH}$. This decrease can be explained by (i) the low $\mathrm{OH}^{-}$concentration which hinders the formation of $\mathrm{OH}^{\circ}$ and subsequently reduces the degradation rate and (ii) an inhibition of photocatalytic reactions with chloride ions which adsorb on the surface of $\mathrm{TiO}_{2}$ and compete with MLN on the adsorption sites. At a $\mathrm{pH}$ around 5, the inhibition of $\mathrm{Cl}^{-}$is small compared to the degradation rate obtained in water (Figure 10), but this inhibition increases with $\mathrm{Cl}^{-}$concentration particularly at low $\mathrm{pH}$ values. Similar results were reported for the degradation of nitrophenols by AUGUGLIARO et al. (1991) and by CHEN and RAY (1998). When $\mathrm{HClO}_{4}$ is used, the degradation rate increases with perchlorate ion concentration which cancels the effect of $\mathrm{pH}$ observed with $\mathrm{HCl}$. Similar results were obtained by IRMAK et al. (2004) who showed that oxyhalogens such as $\mathrm{IO}_{4}^{-}, \mathrm{BrO}_{3}$, $\mathrm{ClO}_{3}^{-}$increase the degradation rate of organic pollutants by capturing the electrons ejected from $\mathrm{TiO}_{2}$ so that the probability of recombination of $\mathrm{e}^{-/ \mathrm{h}^{+}}$pairs will decrease. 


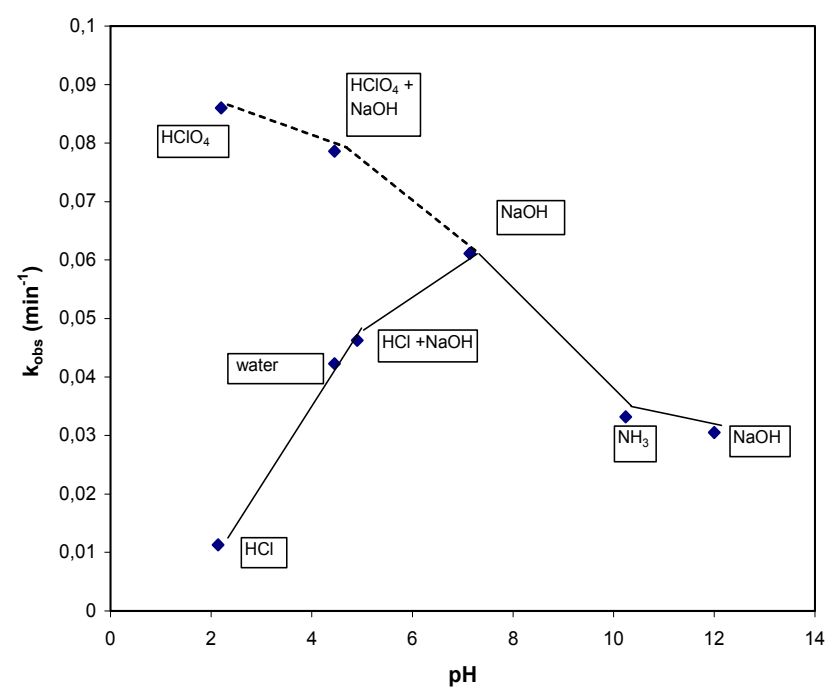

Figure 10. Effect of $\mathrm{pH}$ on the pseudo-first-order rate constant. Influence du pH sur la pseudo-constante d'ordre 1.

- At $\mathrm{pH}>6.3$, the degradation rate decreased with the increasing $\mathrm{pH}$ value beyond the pzc. In this case, both bases used have a low influence on the rate constant. In this range of $\mathrm{pH}$, the high $\mathrm{OH}^{-}$ion content of the system enhances the electron-holes separation. However further increments of $\mathrm{pH}$ would retard the rates. This can be explained by the effect of charge repulsion between $\mathrm{TiO}_{2}$ particles (negatively charged) and MLN molecules or hydroxide ions. Repulsion between $\mathrm{TiO}^{-}$species present on the $\mathrm{TiO}_{2}$ surface and MLN would occur through more atoms with negative partial charges localized on the nitrogen and oxygen of the urea function (Figure 11). These charges were calculated using hyperchem 6.0 software by the AM1 method.

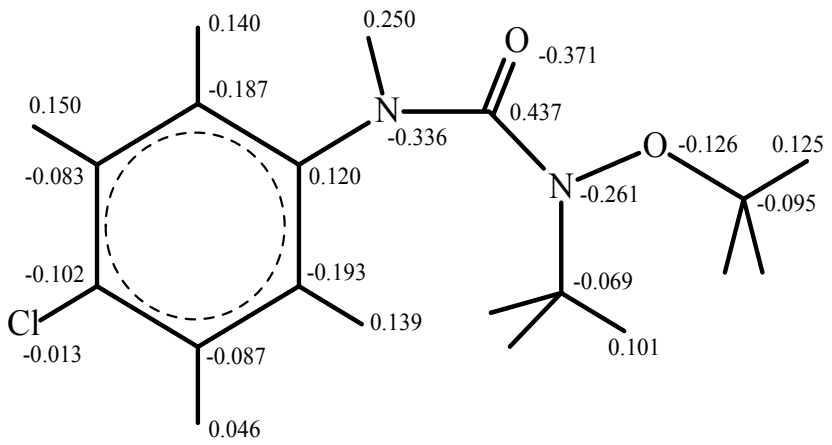

Figure 11. Charge densities on monolinuron atoms. Densité de charge sur les atomes du monolinuron.

\section{CONCLUSION}

The photocatalytic degradation of two phenylurea herbicides (LN and MLN) in aqueous solution has been studied in the presence of $\mathrm{TiO}_{2}$ Degussa P-25 under simulated solar irradiation. Results show that photocatalytic degradation of both herbicides follows pseudo-first-order decay. The kinetics of degradation of MLN and LN are very similar even though the benzene ring is substituted with $2 \mathrm{Cl}$ atoms. This study pointed out the dependence of the photocatalytic rates on operating conditions such as $\mathrm{TiO}_{2}$ dosage, herbicide concentration, photonic flux and $\mathrm{pH}$, which are mainly related to the reactions at the interface of the catalyst such as adsorption / desorption equilibrium, electrostatic interaction and activation of the catalyst surface with light.

\section{ACKNOWLEDGEMENT}

We thank Degussa-Hüls-France for suppling $\mathrm{TiO}_{2} \mathrm{P}-25$ and the Ministère Algérien de l'Enseignement supérieur et de la Recherche for their financial support.

\section{BILBLIOGRAPHIC REFERENCES}

AL-SAYYED G., J.C. D'OLIVEIRA. and P. PICHAT (1991). Semiconductor-sensitized photodegradation of 4-chlorophenol in water. J. Photochem. Photobiol. A. Chem., 58, 99-114.

AMINE-KHODJA A., A. BOULKAMH and C. RICHARD (2005). Phototransformation of metobromuron in the presence of $\mathrm{TiO}_{2}$. Appl. Catal. B. Environ., 59, 147-151.

AUGUGLIARO V., V. LODDO, L. PALMISANO and M. SCHIAVELLO (1995). Performance of heterogeneous photocatalytic system: influence of operational variables on photoactivity of aqueous suspension of $\mathrm{TiO}_{2}$. J. Catal.,153, 32-40.

BAHNEMANN D., J. CUNNINGHAM, M.A. FOX, E. PELIZZETTI, P. PICHAT and N. SERPONE (1994). Aquatic and surface photochemistry. In: HELZ, G.R., R.G. ZEPP and D.G. CROSBY (Editors), Lewis Pub., Boca Raton, FL, Ch. 21, 261-316.

CHEN D. and A.K. RAY (1998). Photodegradation kinetics of 4-nitrophenol in $\mathrm{TiO}_{2}$ suspension. Water Res., 32, 3223-3234. 
CUNNINGHAM J. and S. SRIJARANAI (1991). Adsorption of model pollutants onto $\mathrm{TiO}_{2}$ particles in relation to photoremediation of contaminated water. In: HELZ, G.R., R.G. ZEPP and D.G CROSBY (Editors), Aquatic and surface photochemistry, Lewis Pub., Boca Raton, FL., pp. 317-348.

D'OLIVEIRA J.C., G. AL-SAYYED and P. PICHAT (1990). Photodegradation of 2- and 3- chlorophenol in $\mathrm{TiO}_{2}$ aqueous suspensions. Environ. Sci. Technol., 24, 990-996.

HEREDIA J.D., J. TORREGROSA, J.R. DOMINGUEZ and J.A. PERES (2001). Oxidation of p-hydroxybenzoic acid by UV radiation and by $\mathrm{TiO}_{2} / \mathrm{UV}$ radiation: comparison and modelling of reaction kinetic. J. Hazard. Mater., 83, 255-264.

HERRMANN J.M. (1999). Heterogeneous photocatalysis: fundamentals and applications to the removal of various types of aqueous pollutants. Catal.Today, 53, 115-129.

INEL Y. and A.N. OKTE (1996). Photocatalytic degradation of malonic acid in aqueous suspensions of $\mathrm{TiO}_{2}$ : an initial kinetic investigation of $\mathrm{CO}_{2}$ photogeneration. J. Photochem. Photobiol. A. Chem., 96, 175-180.

LE CAMPION L., C. GIAMOTTI and J. OUAZZANI (1999). Photocatalytic degradation of 5-nitro-1,2,4-triazol3 -one $\mathrm{NTO}$ in aqueous suspension of $\mathrm{TiO}_{2}$. Comparison with fenton oxidation. Chemosphere, 38, 1561-1570.

MARINAS A., C. GUILLARD, J.M. MARINAS, A. FERNANDEZ-ALBA, A. AGUÊRA and J.M. HERRMANN (2001). Photocatalytic degradation of pesticide-acaricide formetanate in aqueous suspension of $\mathrm{TiO}_{2}$. Appl. Catal. B. Environ., 34, 241-252.

NARGIELLO M. and T. HERZ (1993). Physical-chemical characteristics of P-25 making it extremely suited as the catalyst in photodegradation of organic compounds. In: OLLIS, D.F., H. AL-EKABI (Editors), Proceedings of the $1^{\text {st }}$ International conference on $\mathrm{TiO}_{2}$ photocatalytic purification and treatment of water and air. Amsterdam, Elsevier Sci., 801-807.

OKAMOTO K., Y. YAMAMOTO, H. TANAKA and A. ITAYA (1985). Kinetics of heterogeneous photocatalytic decomposition of phenol over anatase $\mathrm{TiO}_{2}$ powder. Bull. Chem. Soc. Japan, 58, 2023-2028.

OLLIS D.F., E. PELIZZETTI and N. SERPONE (1989). Heterogeneous photocatalysis in the environment: application to water purification. In: Photocatalysis: fundamentals and applications. N. SERPONE and
E. PELIZZETTI (Editors), Wiley Interscience, New York, pp. 603-637.

OLLIS D.F. and H. AL-EKABI (1993). Photocatalytic purification and treatment of water and air. ELSEVIER (Editor), Amsterdam.

PARRA S., J. OLIVERO and C. PULGARIN (2002). Relationships between physicochemical properties and photoreactivity of four biorecalcitrant phenylurea herbicides in aqueous $\mathrm{TiO}_{2}$ suspension. Appl. Catal. B. Environ., 36, 75-85.

PRAMAURO E. and M. VINCENTI (1993). Photocatalytic degradation of monuron in aqueous $\mathrm{TiO}_{2}$ dispersions. Environ. Sci. Technol., 27, 1790-1795.

IRMAK S., E. KUSVURAN and O. ERBATUR (2004). Degradation of 4-chloro-2-methylphenol in aqueous solution by UV irradiation in the presence of titanium dioxide. Appl. Catal. B. Environ., 54, 85- 91.

TAPOLOV A., D. MOLNÀR-GÀBOR, M. KOSANIÉ and B. ABRAMOVIÉ (2000). Photomeniralisation of the herbicide mecoprop dissolved in water sensitized by $\mathrm{TiO}_{2}$. Water Res., 34, 1473-1478.

TERZIAN R. and N. SERPONE (1995). Heterogeneous photocatalyzed oxidation of creosote components: mineralization of xylenols by illuminated $\mathrm{TiO}_{2}$ in oxygenated aqueous media. J. Photochem. Photobiol. A. Chem., 89, 163-175.

TOMLIN C. (2000). The pesticide manual, $12^{\text {th }}$ ed., CROP. PROTECTION PUBLICATIONS, Surrey, UK, 626, 709 .

VINCZE L. and T.J. KEMP (1995). Light flux and light flux density dependence of the photomineralisation rate of 2,4dichlorophenol and chloroacetic acid in the presence of $\mathrm{TiO}_{2}$. J. Photochem. Photobiol. A. Chem., 87, 257-260.

VULLIET E., J.M. CHOVELON, C. GUILLARD and J.M. HERRMANN (2003). Factors influencing the photocatalytic degradation of sulfonylurea herbicides by $\mathrm{TiO}_{2}$ aqueous suspension. J. Photochem. Photobiol. A. Chem., 159, 71-79.

WONG C.C. and W. CHU (2003). The direct photolysis and photocatalytic degradation of alachlor at different $\mathrm{TiO}_{2}$ and UV sources. Chemosphere, 50, 981-987. 